\title{
An investigation of somatosensory profiles in work related upper limb disorders: a case-control observational study protocol
}

\author{
Niamh Moloney ${ }^{1 *}$, Toby Hall ${ }^{2,3}$, Catherine Doody ${ }^{1}$
}

\begin{abstract}
Background: Work related upper limb disorders constitute $45 \%$ of all occupational diseases and are a significant public health problem. A subgroup, non specific arm pain (NSAP), remains elusive in terms of understanding its pathophysiological mechanisms with its diagnosis based on the absence of specific clinical findings. One commonly proposed theory is that a neural tissue disorder is the primary dysfunction in NSAP and findings from previous studies lend some support to this theory. However, it is not clear if changes identified are simply a consequence of ongoing pain rather than due to specific neural changes. The presence of neuropathic pain has been investigated in several other musculoskeletal conditions but currently, there is no specific diagnostic tool or gold standard which permits an unequivocal diagnosis of neuropathic pain. The purpose of this study is to further describe the somatosensory profiles in patients with NSAP and to compare these profiles to a group of patients with MRI confirmed cervical radiculopathy who have been previously classified as having neuropathic pain.

Methods/Design: Three groups of participants will be investigated: Groups 1 and 2 will be office workers with either NSAP or cervical radiculopathy and Group 3 will be a control group of non office workers without upper limb pain. Participants will undergo a clinical assessment, pain questionnaires (LANSS, Short Form McGill, DASH and TSK) and quantitative sensory testing comprising thermal detection and pain thresholds, vibration thresholds and pressure pain thresholds.

Discussion: The spectrum of clinically suspected neuropathic pain ranges from more obvious conditions such as trigeminal neuralgia to those with vague signs of nerve disorder such as NSAP. A thorough description of the somatosensory profiles of NSAP patients and a comparison with a more defined group of patients with evidence of neuropathic pain will help in the understanding of underlying neurophysiology in NSAP and may influence future classification and intervention studies relating to this condition.
\end{abstract}

\section{Background}

Work related upper limb disorders (WRULD) (often called repetitive strain injury) are a significant public health problem, estimated to constitute $45 \%$ of all occupational diseases [1]. Non specific arm pain (NSAP) constitutes a subgroup of WRULD [2-5] and has been defined as diffuse pain in the forearm (which can also involve the neck, arm, wrist and hand) in the absence of evidence of a specific upper limb disorder [2-6].

\footnotetext{
* Correspondence: n_moloney@yahoo.com

'UCD School of Public Health, Physiotherapy and Population Science, University College Dublin, Belfield, Dublin 4, Ireland
}

University College Dublin, Belfield, Dublin 4, reland

\section{Aetiology of NSAP}

NSAP is a vague clinical entity, the pathophysiological mechanisms of which remain unclear. While it is quite feasible that pain in NSAP is nociceptive in origin e.g. from muscle tissue, an underlying dysfunction of the nervous system has been proposed [7-9]. A mechanisms based approach to understanding pain has been advocated [10] but currently, there are no gold standards or valid or reliable methods to diagnose underlying neurophysiological pain mechanisms. It is proposed that the use of a pain mechanisms classification system would be valuable in identifying sub-groups of patients who are most likely to require different treatment strategies [10]. There is some evidence to suggest that patients treated

(C) 2010 Moloney et al; licensee BioMed Central Ltd. This is an Open Access article distributed under the terms of the Creative Commons Attribution License (http://creativecommons.org/licenses/by/2.0), which permits unrestricted use, distribution, and reproduction in any medium, provided the original work is properly cited. 
according to symptom specific classification systems have superior outcomes to those who are not [11].

A number of algorithms for assessing the presence of neuropathic pain exist. They include the use of pain questionnaires and combinations of pain descriptors and clinical testing [12-14]. Treede et al's [14] proposed algorithm for the assessment of neuropathic pain involves the development of a working hypothesis of "possible" neuropathic pain based on clinical information, pain mapping and history relating to the onset of pain. If further evidence by way of clinical examination, neurophysiological tests and laboratory tests such as MRI can be yielded, then patients can be categorised further as "probable" or "definite" neuropathic pain. However, this model requires further testing in terms of reliability and validity. In addition, there are a number of pain questionnaires for the classification of neuropathic pain (e.g. Leeds Assessment for Neuropathic Signs and Symptoms (LANSS), Neuropathic Pain Questionnaire, pain DETECT). Again, all of these methods require further validation before their use as a diagnostic tool can be advocated.

Another means of assessing pain mechanisms is the use of quantitative sensory testing (QST). QST is useful in quantifying mechanical and thermal allodynia and hyperalgesia and may help to characterise painful neuropathic syndromes as well as clarifying some of their pathophysiological mechanisms [15]. However, QST alone cannot conclusively determine the presence of neuropathic pain.

\section{Evidence for the presence of Neuropathic Pain in NSAP}

In relation to the clinical presentation in NSAP, many researchers have reported presenting symptoms which are consistent with those of neuropathic pain, for example, paraesthesia, dysaesthesia, weakness, burning pain, cramping, slowing of fine movements and allodynia $[5-9,16,17]$. This has led to the initial hypothesis that NSAP may have an underlying neuropathic pain component. Clinical studies have identified the presence of mechanical hyperalgesia involving the peripheral nerve trunks in this population [16-19]. Peripheral nerve trunk mechanical hyperalgesia is tested using upper limb neurodynamic tests and these have been identified as useful indicators of central nervous system hyperexcitability [20]. They may also be reflective of localised peripheral nerve inflammation [21] or indicative of peripheral nerve sensitisation [12]. Smart et al., (2009) [13] have found neural tissue provocation tests for the lower limb (straight leg raise) a useful indicator of peripheral nerve sensitisation while Scholz et al., (2009)[22] have also identified the straight leg raise test within a battery of tests as useful for the differentiation of neuropathic pain mechanisms in LBP. However, the correlation of neurodynamic tests with qualitative measures of pain and quantitative measures of nerve function or indeed the presence of neuropathic pain is unknown in NSAP.

Various QST measures have been used to investigate the somatosensory profiles of patients with NSAP; however the results of these studies reveal conflicting evidence. Greening et al., $[23,24]$ have identified changes in flare response, vasoconstriction and vibration in office workers with NSAP when compared with office workers without pain or non office workers. Their findings in relation to vibration are supported by some researchers [25-28], but not others [29,30].

\section{QST findings in musculoskeletal disorders}

While pressure pain thresholds or thermal QST have not been specifically investigated in NSAP, studies of other working populations have yielded mixed results. Increased sensitivity to pressure has been found in the shoulder and neck muscles of butchers [31], secretaries [32] and manufacturing workers [33]. Contrary to this, Johnston et al., [34] found office workers with neck pain showed no difference in pressure pain thresholds (PPT) over the neck muscles in comparison to controls but they did have lower PPT at median nerve and tibialis anterior sites. Increased sensitivity to pressure has also been found in whiplash and cervical radiculopathy patients [35,36]. In relation to thermal QST, Johnston et al., [34] found that office workers with mild neck pain and disability had decreased heat pain thresholds and were more sensitive to cold pain than controls or office workers without pain. Furthermore, alterations in thermal detection thresholds have been found in the upper limbs of patients with whiplash and cervical radiculopathy [37]. One interesting finding in this study by Chien et al. is the presence of non-symptomatic to symptomatic side differences in the cervical radiculopathy group which did not exist in the whiplash group. Whilst further investigations are warranted to elucidate the significance of this finding, it may reflect a difference between neuropathic versus non-neuropathic pain presentations.

Recent investigations into work related neck pain [34]; diffuse upper limb pain [28], low back pain [38], whiplash [20,36], patellofemoral pain syndrome [39], fibromyalgia and complex regional pain syndrome [40] have shown that these conditions may have a neuropathic pain component. However, many of these studies show positive findings on both the asymptomatic and symptomatic sides, indicating that change may just be reflective of alterations in somatosensory processing associated with pain i.e. central plasticity from nociceptive or inflammatory pain as opposed to true neuropathic pain [14].

Clearly, there is much debate as to whether NSAP, which appears to have features of neuropathic pain, is indeed a neuropathic disorder. Furthermore, there are 
currently no gold standards with which to classify pain as definitively neuropathic. The purpose of this study is to comprehensively describe the somatosensory profiles in patients with NSAP and to compare them to somatosensory profiles in asymptomatic subjects and subjects with cervical radiculopathy. It is hypothesised that some of the NSAP group may demonstrate a similar presentation to that of cervical radiculopathy, indicating a probable neuropathic pain presentation.

\section{Methods/Design}

\section{Objectives}

The objectives of this study are to:

- Describe the somatosensory profiles of subjects with NSAP in terms of neurological examination, qualitative measures of pain, neural tissue provocation tests and QST.

- Describe impairment and disability associated with NSAP by means of the Disabilities of the Arm, Shoulder and Hand (DASH) and SF-36 questionnaires.

- Investigate for correlations between clinical examination findings, QST profiles and questionnaire derived pain profiles in subjects with NSAP.

- Compare somatosensory profiles of subjects with NSAP to those with cervical radiculopathy and asymptomatic controls.

\section{Study design}

A case-control observational design will be used to assess quantitative and qualitative sensory features as well as pain profiles in two patient groups and a control group.

\section{Ethical Approval}

The study was approved by the Human Research Ethics Committee - Life Sciences in University College Dublin on January 23rd 2009.

\section{Participants}

One hundred and fifty consenting male and female subjects, aged 18-65 years will be recruited comprising three equal groups of (1) Patients with NSAP, (2) Patients with cervical radiculopathy and (3) Age and gender matched controls.

\section{- Groups 1 and 2: NSAP and Cervical Radiculopathy subjects}

Inclusion criteriaAll participants from patient groups will be office workers who have significant unilateral upper limb pain as defined by a numerical rating score of $\geq 3 / 10$ [31,41], who spend more than $40 \%$ of their working week using desktop equipment [24] and have been in their current employment or similar (i.e. involving office work/keyboard operation) for at least two years [34]. More specific information regarding diagnostic criteria for each patient group is outlined in the next section. Patients will be recruited from local orthopaedic outpatient and occupational health departments of Dublin hospitals and physiotherapy practices and also from the staff and student population of University College Dublin.

\section{- Group 3: Control Subjects}

Inclusion criteriaFifty age and gender matched subjects will be included if they have no history of significant neck, scapular or shoulder pain over the past 12 months (significant pain is defined as pain $\geq 3 / 10$ on a visual analogue scale $[31,41]$ and do not use desktop equipment for more than $40 \%$ of their working week [24]. The control group will be recruited from staff/students at University College Dublin, St Vincent's University Hospital staff and the local community.

\section{Exclusion criteria for all participants}

Subjects will be excluded if they are seeking compensation for their injury or if they have any of the following: bilateral upper limb pain, neurological disorders, generalized musculoskeletal disorders e.g. rheumatoid arthritis or fibromyalgia, a history of low back pain and/or low back related leg pain over the previous 6 months, a history of migraine over the previous 6 months, previous surgery or trauma to the upper quadrant, diabetes or endocrine disorders, epilepsy or any psychiatric disorders. Participants taking anti-epileptic or anti-depressant medication, or who are undergoing chemotherapy/radiotherapy will also be excluded.

\section{Group Selection}

\section{Screening and Allocation to study groups}

Participants will be interviewed and screened for general inclusion and exclusion criteria (Figure 1: Study Protocol). Participants with cervical radiculopathy will be recruited from a local spinal surgery service and identified by the presence of radicular pain in the upper limb, positive upper limb neurodynamic tests, Spurling's test, and Valsalva manoeuver as well as MRI confirmation of nerve compression $[42,43]$. The MRI scans of all patients will be reviewed by a radiologist and those patients with evidence of intervertebral disc protrusion and associated nerve root compression will be identified. Nerve root compression will be classified as absent, minimal, moderate or severe [44].

All other participants will be screened by means of a subjective examination, pain area mapping and a clinical orthopaedic examination to identify participants with NSAP and to exclude patients with all other specific upper limb disorders according to classification criteria outlined by Boocock et al, [2]. The classification criteria for NSAP are listed in Table 1, with classification criteria for specific upper limb disorders listed in Additional file 1 . 
Table 1 Classification criteria for NSAP

\begin{tabular}{lll}
\hline DEFINITION NSAP & SYMPTOMS & SIGNS \\
\hline $\begin{array}{l}\text { Pain in the arm in the absence of a specific } \\
\text { diagnosis or pathology }\end{array}$ & $\begin{array}{l}\text { Pain in the forearm and failure to meet the } \\
\text { diagnostic criteria of specific disorders } \\
\text { Symptoms may include: } \\
\text { Loss of function } \\
\text { Weakness in arms and hands } \\
\text { Cramp a specific pathology that } \\
\text { Muscle tenderness } \\
\text { Allodynia } \\
\text { Slowing of fine movements Clumsiness }\end{array}$ \\
\hline
\end{tabular}

Boocock et al., 2009

\section{Data Collection}

General information regarding subject health, work status, and medication use will be obtained. Information regarding the work practices of each individual will also be collected, including how many hours they spend using desktop, laptop and mouse equipment.

\section{Physical Examination Part B}

All measures will be performed by the principal investigator. Whilst independent screening and allocation to groups would be preferable, this is not feasible within the current study and possible resultant bias is acknowledged by the authors.

\section{Neurological examination}

A bedside neurological evaluation of the upper limb will be carried out on all subjects, including assessment of upper limb reflexes, myotomes and sensation.

- Deep tendon reflexesDeep tendon reflexes will be assessed for Biceps (C5/6), Brachioradialis (C5/6), Pronator Teres (C6/7) and Triceps (C7/8) [45,46]. As any grade of reflex can be considered normal, reflexes will be rated normal or abnormal by comparison to the other side as it is considered that asymmetry is the most helpful assessment [47]. If reflexes are found to be abnormal, they will be further categorised as absent/ diminished or increased [48]. Interrater reliability using this grading system has been found to be good for the biceps reflex [48].

- MyotomesMyotomes will be assessed by testing the strength of muscles corresponding to each nerve root according to previously published guidelines [49-52]. Interrater reliability for manual muscle tests ranges from $\kappa=0.53-0.83$ when measuring muscle strength as normal or reduced [48]

- DermatomesSensation will be assessed for detection of light touch (using cotton wool) and sharp-blunt discrimination (using a pin prick). Stimuli will be applied circumferentially repeatedly around the participant's upper limbs so that all dermatomes will be assessed, with both limbs assessed for comparison. Each finger will be assessed separately [48]. When a difference is detected the area will be assessed in more detail and a map of the area of altered sensation will be recorded on a body chart to determine if the area follows a dermatomal pattern, is consistent with a particular peripheral nerve or if it corresponds to somatic referred pain or trigger point referral patterns $[53,54]$. Each sensory level will be graded as reduced, normal or increased [48]. Interrater reliability for assessment of dermatomes has been found to be moderate $[48,50]$. In addition, areas of heightened sensation will be assessed for signs of allodynia or hyperalgesia [15].

\section{Neural Tissue Provocation Tests}

Mechanosensitivity of upper limb neural tissue will be assessed using upper limb neurodynamic tests and nerve palpation.

- Neurodynamic TestLongitudinal tests of the brachial plexus and peripheral nerves of the upper limb called the upper limb neurodynamic tests (ULNT) have been shown to reliably detect neural tissue mechanosensitivity [55]. The ULNT ${ }^{1}$ has received the most research investigation and will be used in this study [16,35,56-60]. Interrater reliability of the $\mathrm{ULNT}^{1}$ has been shown to be moderate $(\kappa=0.54)$ [43] and good $(\kappa=0.73)$ [48].

With the participant supine the test will be performed in the following sequence: gentle scapular depression, shoulder abduction, forearm supination combined with wrist and finger extension, shoulder external rotation and elbow extension [37]. Participants will be asked to indicate to the examiner during elbow extension when they first perceive pain anywhere along the tested arm. The angle of elbow extension will then be measured using a standard goniometer aligned along the midhumeral shaft, medial epicondyle and ulnar styloid [61] and the participant will be asked to indicate their pain experienced during the test using the numerical rating scale [37].

- Nerve PalpationThe median, radial and ulnar nerves will be digitally palpated to assess for mechanosensitivity [62]. Nerve palpation has been used in previous studies and has shown to be reproducible [50] and moderately reliable [48]. Moderate digital pressure will be applied to each nerve at the following sites: the median nerve in the cubital fossa medial to and immediately adjacent to the biceps tendon; the ulnar nerve in the groove 
between the median epicondyle and the olecranon, the radial nerve in the upper arm where it passes through the intermuscular septum between the medial and lateral heads of triceps [63-65]. A test will be deemed positive if pain or symptoms are elicited [48].

\section{Quantitative Sensory Testing}

A familiarisation trial will be performed on the brachioradialis muscle for all measures of QST prior to testing [35]. The sequence of examination will be randomised using a random number generator in order to control for the effects of fatigue.

\section{- Thermal Testing}

All tests will be performed using a NeuroSensory Analyser (TSA 2001 II Medoc, Israel). The Peltier thermode $(16 \times 16 \mathrm{~mm})$ will be attached directly over areas in the hand innervated by C6 (dorsum of the first metacarpal), C7 (dorsum of the second metacarpal) and C8 (dorsum of the fifth metacarpal). Tibialis anterior will be used as a reference point [35]. The temperature of the NeuroSensory Analyser will be preset to a baseline of 30 degrees Celsius and increased or decreased at a rate of 1 degree per second. Thermal detection (Warm, Cold) and pain (Heat, Cold) thresholds will be measured using the method of limits [35]. Standardised instructions will be read out to the participants prior to testing. In the case of warm and cold detection thresholds participants will be asked to indicate when they notice the temperature of the thermode changing from neutral to warm/ cool and in the case of heat and cold pain thresholds participants will be asked to indicate when they notice the heat or cold becoming painful. Participants will be asked to press a patient control switch at each point. Participants will be advised that this is not a measure of pain tolerance. All measures will be taken in triplicate with the mean values used for analysis [66]. Thermal QST measures have been shown to demonstrate reasonable test-retest reliability $[41,66,67]$.

\section{- Vibration thresholds}

A Vibrameter (VSA 3000 II 2001 Medoc, Israel) will be used to measure vibration perception thresholds. Readings will be taken over the areas of the hand innervated homonymously by C6 (palmar aspect of the first metacarpal), C7 (palmar aspect of the second metacarpal) and C8 dermatomes (dorsum of the fifth metacarpal). Triplicate recordings will be taken at each site and the mean values used for analysis [35]. Test - retest reliability and [68-72] inter - rater reliability [69] has been shown to be consistently good for vibration measurements.

\section{- Pressure Pain Thresholds}

Pressure pain thresholds (PPT) will be determined using a hand held pressure algometer with a probe size of $1 \mathrm{~cm} 2$ (Somedic AB, Farsta, Sweden) and an application rate of $40 \mathrm{kPa} / \mathrm{s}$. PPT will then be recorded bilaterally over the median, ulnar and radial nerves, the sites of which will correspond to the nerve palpation sites outlined above [65]. All sites will be marked with a skin marker to ensure accuracy [73]. The participant will be instructed to press a patient control switch when the sensation under the probe changes from one of pressure to one of pressure and pain. All measures will be taken in triplicate and the mean value was used for analysis [35]. PPT measures have been repeatedly shown to demonstrate good intra and inter rater reliability both in general [74-78] and in sites specific to the upper limb nerves [65]

\section{Pain Assessment}

Participants from both patient groups will be asked to complete a detailed assessment of pain intensity and quality. A clinically administered LANSS questionnaire will be used for specific identification of neuropathic pain. The LANSS has been tested and validated in several settings [79-81]. A Short Form McGill Pain Questionnaire will be administered [82], which has been validated for the measurement of sensory and affective dimensions of pain [83]. The McGill includes a visual analogue scale and present pain index $[82,84]$. A Tampa Scale for Kinesiophobia will be used as this has been shown to be a reliable assessment tool for chronic pain [85-87,82-84] while the DASH $[88,89]$ and SF-36 will be used as measures of disability and functional impairment in these patient groups. Furthermore, three proposed algorithms, which are currently under review by other researchers, will be used as aids in differentiation of pain mechanisms for all symptomatic subjects [12-14].

\section{Data Management}

Participant data will be coded to ensure anonymity of participants and stored at a central database at the School of Physiotherapy and Performance Science, University College Dublin, Ireland.

\section{Sample size/power calculation}

Power analysis: Sample size was calculated based on mean and standard error vibration threshold data from a study by Greening et al., (2003). A sample of size of 50 patients with NSAP, 50 patients with cervical radiculopathy and 50 matched control subjects will be required to detect a medium effect size (0.5) with 0.8 power and 0.05 two tailed significance level.

\section{Statistical Analysis}

Descriptive statistics will be calculated for all outcome measures. Differences in categorical variables between groups will be analysed using a Chi Square Test. A one way ANOVA with Student-Newman-Keuls test will be used for Post-hoc comparisons for all continuous normally distributed data.

\section{Study Limitations}

- The screening, group allocation and data collection will all be carried out by the principal investigator. 
Whilst independent screening and group allocation would be preferable, this is not feasible. The authors acknowledge the bias inherent in this.

- NSAP participants could be investigated with MRI and/or nerve conduction studies to rule out any identifiable nerve dysfunction and the authors acknowledge this limitation.

\section{Discussion}

\section{Scientific significance}

WRULD are a significant public health problem and NSAP constitutes a diagnostic category for which our understanding of pathophysiological mechanisms remains unclear. The spectrum of clinically suspected neuropathic pain ranges from more obvious conditions such as trigeminal neuralgia to those with vague signs of nerve disorder such as NSAP. A thorough description of the somatosensory profiles of NSAP patients and a comparison with a more defined group of patients with probable neuropathic pain will help in the understanding if underlying neurophysiology in this condition and may influence future classification and intervention studies relating to NSAP.

Additional file 1: Classification Criteria for Work Related Upper Limb Disorders (Boocock 2009). Consensus diagnostic criteria for specific upper limb disorders.

Click here for file

[http://www.biomedcentral.com/content/supplementary/1471-2474-1122-S1.DOC]

\section{Abbreviations}

WRULD: Work related upper limb disorders; NSAP: Non specific arm pain; QST: Quantitative Sensory Testing; PPT: Pressure Pain Threshold; LANSS: Leeds Assessment of Neuropathic Symptoms and Signs; ULNT: Upper limb neurodynamic tests; DASH Disabilities of the Arm; Shoulder and Hand; TSK: Tampa Scale of Kinesiophobia.

\section{Acknowledgements}

The authors would like to thank Dr. Caroline O'Kelly, Statistician for her advice on data analysis for this study. This study is funded by the Irish Research Council for Science Engineering and Technology.

\section{Author details}

'UCD School of Public Health, Physiotherapy and Population Science, University College Dublin, Belfield, Dublin 4, Ireland. ${ }^{2}$ School of Physiotherapy, Curtin University of Technology, G.P.O. Box U1987, Perth, WA 6845, Australia. ${ }^{3}$ Manual Concepts, P.O. Box 1236, Booragoon, WA 6954, Australia.

\section{Authors' contributions}

NM, CD and TH all participated fully in the development of the study protocol. NM drafted this manuscript which was reviewed and critiqued by $\mathrm{CD}$ and $\mathrm{TH}$. All authors read and approved the final manuscript.

\section{Authors' informations}

NM is a Musculoskeletal Physiotherapist with an interest in neural tissue disorders. She is currently a PhD student in University College Dublin.
CD is a Lecturer in Physiotherapy at University College Dublin with a special interest in clinical reasoning and musculoskeletal disorders.

TH is a Specialist Musculoskeletal Physiotherapist and Adjunct Senior

Teaching Fellow at Curtin University of Technology, Perth, Western Australia. His research interests are neural tissue pain disorders and cervicogenic headache.

\section{Competing interests}

The authors declare that they have no competing interests.

Received: 27 May 2009

Accepted: 30 January 2010 Published: 30 January 2010

\section{References}

1. Eurostat work and health in the European Union: A statistical portrait, office for official publications of the European communities. Luxemburg 2004.

2. Boocock MG, Collier JM, McNair PJ, Simmonds M, Larmer PJ, Armstrong B: A Framework for the Classification and Diagnosis of Work- Related Upper Extremity Conditions: Systematic Review. Seminars in Arthritis and Rheumatism 2009, 38:296-311.

3. Harrington J, Carter J, Birrell L, Gromptez D: Surveillance case definitions for work related upper limb pain syndromes. Occupational and Environmental Medicine 1998, 55:264-271.

4. Palmer KT: Pain in the forearm, wrist and hand. Best Practice and Research Clinical Rheumatology 2003, 17:113-115.

5. Sluiter J, Rest K, Frings-Dresen M: Criteria Document for evaluating work relatedness of upper extremity musculoskeletal disorders. Scandinavian Journal of Work Environmental Health 2001, 27:1-102.

6. Greening J, Lynn B: Minor peripheral nerve injuries: an underestimated source of pain?. Manual Therapy 1998, 3(4):187-194.

7. Cohen ML, Arroyo JF, Champion DG, Browne CD: In search of the pathogenesis of refractory cervicobrachial pain syndrome: $A$ deconstruction of the RSI phenomenon. The Medical Journal of Australia 1992, 156:432-436.

8. Novak CB, Mackinnon SE: Nerve Injury in Repetitive Motion Disorders. Clinical Orthopaedics and Related Research 1998, 351:10-20.

9. Woodward C: Repetitive Strain Injury: A Diagnostic Model and Management Guidelines. The Australian Journal of Physiotherapy 1987, 33(2):96-99.

10. Woolf CJ, Bennett GJ, Doherty M, Dubner R, Kidd BL, Koltzenberg M, Lipton R, Loeser JD, Payne R, Torebjork E: Towards a mechanism-basedclassification of pain?. Pain 1998, 77:227-229.

11. Cook C, Brismee jM, Sizer PS: Subjective and objective clinical lumbar spine instability: a Delphi study. Manual Therapy 2006, 11:11-21.

12. Schafer A, Hall T, Briffa K: Classification of low back- related leg pain- A proposed patho-mechanism based approach. Manual Therapy 2009, 14(2):222-230.

13. Smart KM, Blake C, Staines A, Doody C: Clinical indicators of 'nociceptive', 'peripheral neuropathic' and 'central' mechanisms of musculoskeletal pain. A Delphi survey of expert clinicians. Manual Therapy 2009, 15(1):80-87.

14. Treede R-D, Jensen TS, Campbell JN, Cruccu G, Dostrovsky JO, Griffin JW, Hansson P, Hughes R, Nurmikko T, Serra J: Neuropathic Pain: Redefinition and a grading system for clinical and research purposes. Neurology 2008, 70:1630-1635.

15. Cruccu G, Anand P, Attal N, Garcia-Larrea L, Haanpaa M, Jorum E, Serra J, Jensen T: EFNS guidelines on neuropathic pain assessment. European Journal of Pain 2004, 11:153-162.

16. Byng J: Overuse syndromes of the upper limb and the upper limb tension test: a comparison between patients, asymptomatic keyboard workers and asymptomatic non-keyboard workers. Manual Therapy 1997, 2(3):157-164.

17. Champion DG, Cornell J, Browne CD, et al: Clinical observations in patients with the clinical syndrome "repetitive strain injury". Journal of Occupational Health and Safety 1986, 2:107-113.

18. Elvey RL, Quintner JL: A clinical study of RSI. Australian Family Physician 1986, 15:1312-1314.

19. Greening J, Dilley A, Lynn B: In vivo study of nerve movement and mechanosensitivity of the median nerve in whiplash and non-specific arm pain patients. Pain 2005, 115:248-253. 
20. Sterling M, Pedler A: A neuropathic component is common in acute whiplash and associated with a more complex clinical presentation. Manual Therapy 2009, 14(2):173-179.

21. Dilley A, Bove GM: Disruption of axoplasmic transport induces mechanical sensitivity in intact rat C-fibre nociceptor axons. Journal of Physiology 2008, 586(2):593-604

22. Scholz J, Mannion RJ, Hord DE, Griffin RS, Rawal B, Zheng H, Scoffings D, Phillips A, Guo J, Laing RJC, et al: A Novel Tool for the Assessment of Pain: Validation in Low Back Pain. PLoS Medicine 2009, 6(4):e1000047.

23. Greening J, Lynn B: Vibration sense in the upper limbs of patients with $\mathrm{RSI}$ and at risk workers. International Archives of Occupational and Environmental Health 1998, 71:29-34.

24. Greening J, Lynn B, Leary R: Sensory and autonomic function in the hands of patients with non-specific arm pain (NSAP) and asymptomatic office workers. Pain 2003, 104:275-281.

25. Jepsen JR, Thomsen G: A cross sectional study of the relation between symptoms and physical findings in computer operators. BMC Neurology 2006, 6(40).

26. Laursen $L H$, Jepsen JR, Sjogaard G: Vibrotactile sense in patients with different upper limb disorders compared with a control group. International Archives of Occupational and Environmental Health 2006, 79:593-601.

27. Pilegaard M, Jensen BR: An 18-month follow-up study on vibrotactile sense, muscle strength and symptoms in computer users with and without symptoms. International Archives of Occupational and Environmental Health 2005, 78:48-492.

28. Tucker AT, White PD, Kosek E, Pearson RM, Henderson M, Coldrick AR, Cooke ED, Kidd BL: Comparison of vibration perception thresholds in individuals with diffuse upper limb pain and carpal tunnel syndrome. Pain 2007, 127:263-269.

29. Overgaard E, Brandt LPA, Ellemann K, Mikkelsen S, Andersen JH: Tingling/ numbness in the hands of computer users: neurophysiological findings from the NUDATA study. International Archives of Occupational and Environmental Health 2004, 77:S21-S25.

30. Sanden H, Edblom M, Ekman A, Terenbaum A, Wallin GB, Hagberg M: Normal nerve conduction velocity and vibrotactile perception thresholds in computer users. Int Arch Occup Environ Health 2005, 78:239-242.

31. Madeleine $P$, Lundager B, Voigt M, Arendt-Nielsen L: Sensory manifestations in experimental and work-related chronic neck-shoulder pain. European Journal of Pain 1998, 2:251-260.

32. Hagg GM, Sastrom A: Load pattern and pressure pain threshold in the upper trapezius muscle and psychosocial factors in medical secretaries with and without shoulder neck disorders. International Archives of Occupational and Environmental Health 1997, 69:423-432.

33. Gold JE, Punnett $L$, Katz JN: Pressure pain thresholds and musculoskeletal morbidity in automobile manufacturing workers. International Archives of Occupational and Environmental Health 2006, 79:128-134.

34. Johnston $V$, Jimmieson $N L$, Jull G, Souvlis T: Quantitative sensory measures distinguish office workers with varying levels of neck pain and disability. Pain 2008, 137:257-265.

35. Chien A, Eliav E, Sterling M: Hypoesthesia occurs in acute whiplash irrespective of pain and disability levels and the presence of sensory hypersensitivity. Clinical Journal of Pain 2008, 24(9):759-766.

36. Chien A, Eliav E, Sterling M: Hypoaesthesia occurs with sensory hypersensitivity in chronic whiplash - Further evidence of a neuropathic condition. Manual Therapy 2009, 14(2):138-146.

37. Chien A, Eliav E, Sterling M: Whiplash (grade II) and cervical radiculopathy share a similar sensory presentation: An investigation using quantitative sensory testing. Clinical Journal of Pain 2008, 24(7):595-603.

38. Freynhagan R, Rolke R, Baron R, Tolle TR, Rutjes A, Schu S, Treede R-D: Pseudoradicular and radicular low- back pain- $A$ disease continuum rather than different entities? Answers from quantitative sensory testing. Pain 2008, 135(1-2):65-74.

39. Jensen R, Hystad T, Kvale A, Baerheim A: Quantitative sensory testing of patients with long lasting patellofemoral pain syndrome. European Journal of Pain 2007, 11(6):665-676.

40. Fishbain D, Lewis J, Cutler R, Cole B, Rosomoff H, Rosomoff R: Can the neuropathic pain scale disciminate between non-neuropathic and neuropathic pain?. Pain Medicine 2008, 9(1):49-60.

41. Agostinho CMS, Scherens A, Richter H, Schaub C, Rolke R, Treede R-D, Maier C: Habituation and short-term repeatability of thermal testing in healthy human subjects and patients with chronic non-neuropathic pain. European Journal of Pain 2008, 13(8):779-785.

42. Radhakrishnan K, Litchy W, O'Fallon W, Kurland L: Epidemiology of cervical radiculopathy. A population- based study from Rochester, Minnesota, 1976 through 1990. Brain 1994, 117(Pt 2):325-335.

43. Rubinstein SM, Pool JJM, van Tulder MW, Riphagen II, de Vet HCW: A systematic review of the diagnostic accuracy of provocative tests of the neck for diagnosing cervical radiculopathy. Eur Spine J 2007, 16:307-319.

44. Beattie P, Meyers S, Strandford P: Associations between patient report of symptoms and anatomic impairment visible on lumbar magnetic resonance imaging. Spine 2000, 25:819-828.

45. Maitland G, Hengeveld E, Banks K, English K, Edwards B: Examination. Maitland's Vertebral Manipulation Oxford: Butterworth-HeinemannMaitland G, Hengeveld E, Banks K, English K, Six 2001, 133-139.

46. Malanga GA, Campagnolo Dl: Clarification of the pronator reflex. American Journal of Physical Medicine and Rehabilitation 1994, 73:338-340.

47. Malanga GA: The diagnosis and treatment of cervical radiculopathy. Medicine and Science in Sports and Exercise 1997, 29(7):236-245.

48. Schmid AB, Brunner F, Luomajoki H, Held U, Bachmann LM, Kunzer S, Coppieters MW: Reliability of clinical tests to evaluate nerve function and mechanosensitivity of the upper limb peripheral nervous system. BMC Musculoskeletal Disorders 2009, 10(11).

49. American Association of Electrodiagnostic Medicine AAoPMaR: Practice parameter for needle electromyographic evaluation of patients with suspected cervical radiculopathy: summary statement. Muscle Nerve 1999, 22(Suppl):209-211.

50. Jepsen JR, Laursen LH, Hagert C-G, Kreiner Sv, Larsen Al: Diagnostic accuracy of the neurological upper limb examination I: Inter-rater reproducibility of selected findings and patterns. BMC Neurology 2006, 6(8).

51. Rainville J, Noto DJ, Jouve C, Jenis L: Assessment of Forearm Pronation Strength in C6 and C7 Radiculopathies. Spine 2007, 32(1):72-75.

52. Yaar I: The logical choice of muscles for the needle-electromyography evaluation of cervical radiculopathy. Archives of Physical Medicine and Rehabilitation 2005, 86:521-526.

53. Netter FH, Hansen JT: Atlas of Human Anatomy. Teterboro, New Jersey: Icon Learning Systems, 32003.

54. Travell JC: Myofascial pain and dysfunction: The Trigger Point Manual. Baltimore: Williams and Wilkins 1983.

55. Selvaratnam P, Glasgow E, Matyas T: Discriminative validity of the brachial plexus tension test. Fifth Biennial Conference of the MPAA 1988.

56. Coppieters MW, Alshami AM, Hodges PW: An experimental pain model to investigate the specificity of the neurodynamic test for the median nerve in the differential diagnosis of hand symptoms. Archives of Physical Medicine and Rehabilitation 2006, 87:1412-1417.

57. Dilley A, Lynn B, Greening J, DeLeon N: Quantitative in vivo studies of median nerve sliding in respnse to wrist, elbow, shoulder and neck movements. Clinical Biomechanics 2003, 18:899-907.

58. Jepsen JR: Upper limb neuropathy in computer operators? A clinical case study of 21 patients. BMC Musculoskeletal Disorders 2004, 5(26).

59. Sterling $M$, Jull GA, Vincenzino $B$, Kenardy J: Characterisation of Acute Whiplash-Associated Disorders. Spine 2004, 29(2):182-188.

60. Sterling M, Treleaven J, Jull G: Responses to a clinical test of mechanical provocation of nerve tissue in whiplash associated disorder. Manual Therapy 2002, 7(2):89-94.

61. Balstar S, Jull G: Upper trapezius activity during the brachial plexus tension test in asymptomatic subjects. Manual Therapy 1997, 2:144-149.

62. Gifford L: Acute low cervical nerve root conditions: symptom presentations and pathobiological reasoning. Manual Therapy 2001, 6(2):106-115.

63. Butler DS: The Sensitive Nervous System. Adelaide: Noigroup Publications 2000.

64. Mazurek MT, Shin AY: Upper Extremity Peripheral Nerve Anatomy current concepts and applications. Clinical Orthopaedics and Related Research 2001, 383:7-20.

65. Sterling M, Treleaven J, Edwards S, Jull G: Pressure pain thresholds of upper limb peripheral nerve trunks in asymptomatic subjects. Physiotherapy Research International 2000, 5(4):220-229.

66. Yarnitsky D, Sprecher E: Thermal testing: normative data and repeatability for various test algorithms. Journal of Neurological Sciences 1994, 125:39-45. 
67. Wainner LR, Fritz JM, Irrgang JJ, Boninger ML, Delitto A, Allison CS: Reliability and diagnostic accuracy of the clinical examination and patient self-report measures for cervical radiculopathy. Spine 2003, 28(1):52-62.

68. Geber C, Klein T, Rolke R, Magerl W, Dieterich M, Birklein F, Treede R-D: Test retest and interobserver reliability in quantitative sensory testing according to the protocol of the german network of neuropathic pain (DFNS): Poster Presentation. European Journal of Pain 2007, 11(S1):S87.

69. Gelber DA, Pfeifer MA, Broadstone VL, Munster EW, Peterson M, Arezzo JC, Shamoon H, Zeidler A, Clements R, Greene DA, et al: Components of Variance for Vibratory and Thermal Threshold Tesing in Normal and Diabetic Subjects. Journal of Diabetes and its Complications 1995, 9(3):170-176.

70. Grunert BK, Wertsch JJ, Matloub HS, McCallum-Burke S: Reliability of sensory threshold measurement using a digital vibrogram. Journal of Occupational Medicine 1990, 32(2):100-102.

71. Meier PM, Berde CB, DiCanzio J, Zurakowski d, Sethna NF: Quantitative assessment of cutaneous thermal and vibration sensation and thermal pain detection thresholds in healthy children and adolescents. Muscle and Nerve 2001, 24:1339-1345.

72. Rosecrance JC, Cook TM, Goode JD, Schroder MJ: Vibration sensibility testing in the workplace. Day to day reliability. Journal of Medicine 1994, 36(9):1032-1037.

73. Vatine J, Shapira S, Magora F, et al: Electronic pressure algometry of deep pain in volunteers. Archives of Physical Medicine and Rehabilitation 1993, 74:526-530.

74. Antoconi F, Sand T, Lucas GA: Pressure algometry in healthy subjects: interexaminer variability. Scandinavian Journal of Rehabilitation Medicine 1998, 30:3-8.

75. Jones $\mathrm{DH}$, Kilgour RD, Comtois AS: Test- retest reliability of pressure pain threshold measurements of the upper limb and torso in young healthhy women. The Journal of Pain 2007, 8(8):650-656.

76. Nussbaum EL, Downes L: Reliability of clinical pressure-pain algometric measurements obtained on consecutive days. Physical Therapy 1996, 78(2):161-169.

77. Perrson AL, Brogardh C, Sjolund BH: Tender or not tender: Test-retest repeatability of pressure pain thresholds in the trapezius and deltoid muscles of healthy women. Journal of Rehabilitation Medicine 2004, 36:17-27.

78. Vanderweeen $R$, Oostendorp RAB, Vaes P, Duquet W: Pressure algometry in manual therapy. Manual Therapy 1996, 1(5):258-265.

79. Kaki AM, El-Yaski AZ, Youseif E: Identifying neuropathic pain among patients with chronic low-back pain: use of the Leeds Assessment of Neuropathic Symptoms and Signs pain scale. Regional Anesthesia and Pain Medicine 2005, 30:422-428.

80. Potter J, Higgenson IJ, Scadding JW, Quigley CW: Identifying neuropathic pain in patients with head and neck cancer: use of the Leeds Assessment of Neuropathic Symptoms and Signs pain scale. Journal of the Royal Society of Medicine 2003, 96:379-383.

81. Yuccel A, Senocak M, Kocasoy OE, Cimen A, Ertas M: Results of the Leeds Assessment of Neuropathic Symptoms and Signs pain scale in Turkey: a validation study. Journal of Pain 2004, 5:427-432.

82. McGill R: The short - form McGill pain questionnaire. Pain 1987, 30:191-197.

83. Wright KD, Asmundson GJG, McCreary DR: Factorial validity of the shortform McGill pain questionnaire (SF-MPQ). European Journal of Pain 2001, 5(3):279-284.

84. Huskisson EC: Measurement of Pain. The Lancet 1974, 9(2):1127-1131.

85. Crombez G, Vlaeyan JW, Heuts PH, Lysens R: Pain-related fear is more disabling than pain itself: evidence on the role of pain-related fear in chronic back pain disability. Pain 1999, 80:329-339.

86. Kori S, Miller R, Todd D: Kinesphobia: a new view of chronic pain behaviour. Pain Management 1990, 3(35-43).

87. Vlaeyan JW, Haazen IW, Schuerman JA, Kole-Snijders AB, van Eel H: Behavioural rehabilitation of chronic low back pain: comparison of an operant treatment, an operant-cognitive treatment and an operantrespondent treatment. British Journal of Clinical Psychology 1995, 35(Pt 1):95-118.

88. Kitis A, Celik E, Aslan UB, Zencir M: DASH questionnaire for the analysis of musucloskeletal symptoms in industrial workers: A validity and reliability study. Applied Ergonomics 2009, 40:251-255.
89. Viikara-Juntura E: Interexaminer reliability of observations in physical examinations of the neck. Physical Therapy 1987, 67(10):1526-1132.

\section{Pre-publication history}

The pre-publication history for this paper can be accessed here:http://www biomedcentral.com/1471-2474/11/22/prepub

doi:10.1186/1471-2474-11-22

Cite this article as: Moloney et al:: An investigation of somatosensory profiles in work related upper limb disorders: a case-control observational study protocol. BMC Musculoskeletal Disorders 2010 11:22.

\section{Submit your next manuscript to BioMed Central and take full advantage of:}

- Convenient online submission

- Thorough peer review

- No space constraints or color figure charges

- Immediate publication on acceptance

- Inclusion in PubMed, CAS, Scopus and Google Scholar

- Research which is freely available for redistribution

Submit your manuscript at www.biomedcentral.com/submit
C Biomed Central 